\title{
Molecular and Biological Characterization of a Trackable Illinois Isolate of Barley yellow dwarf virus-PAV
}

Jae Sun Moon and Richard G. Allen, Department of Crop Sciences, University of Illinois, 1102 South Goodwin Ave., Urbana 61801; Leslie L. Domier, Department of Crop Sciences, University of Illinois, 1102 South Goodwin Ave., Urbana 61801 and U.S. Department of Agriculture, Agricultural Research Service, Crop Protection Research Unit, 1102 South Goodwin Ave., Urbana, IL 61801; and Adriana D. Hewings, U.S. Department of Agriculture, Agricultural Research Service, Crop Protection Research Unit, 1102 South Goodwin Ave., Urbana, IL 61801

\begin{abstract}
Moon, J. S., Allen, R. G., Domier, L. L., and Hewings, A. D. 2000. Molecular and biological characterization of a trackable Illinois isolate of Barley yellow dwarf virus-PAV. Plant Dis. 84:483-486.

In consecutive annual statewide surveys of the incidence of Barley yellow dwarf viruses (BYDVs) in Illinois wheat and oat fields, 27 BYDV-PAV-like isolates were identified. Using polymerase chain reaction (PCR), the coat protein regions of all 27 isolates were analyzed for restriction fragment length polymorphisms. The PCR products of two isolates, one from each year, had restriction fragment profiles after digestion with HaeIII that differed from the other isolates. The nucleotide sequences of the coat protein regions of a laboratory isolate, BYDVPAV-IL (PAV-IL), two of the isolates with the common restriction profile, and the two isolates with polymorphic profiles were more than $98 \%$ identical. The relatively rare isolate identified during the first year was designated BYDV-PAV-DK1 (PAV-DK1) and further characterized biologically. PAV-DK1 and PAV-IL did not differ significantly in symptom expression, but did differ significantly in rates of transmission by two of the three biotypes of Rhopalosiphum padi examined. Since PAV-DK1 does not occur in high levels in the state of Illinois, and its PCR products have a unique restriction enzyme profile, it has the potential to be used as a traceable isolate in field epidemiological experiments.
\end{abstract}

Additional keywords: aphid transmission, PCR-RFLP

Barley yellow dwarf viruses (BYDVs) cause the most widespread and damaging virus disease of cereal crops worldwide $(4,21)$. BYDVs are members of the Luteoviridae family of plant viruses, including BYDV-PAV, -MAV, -RMV, and -SGV and Cereal yellow dwarf virus (CYDV)-RPV. Symptoms induced by the viruses include yellowing and notching of leaves, stunting, blasting of florets, and death in some grasses and cereals $(8,12)$. BYDVs and CYDV-RPV are phloem limited and persistently transmitted by at least

Corresponding author: L. L. Domier

E-mail: 1-domier@uiuc.edu

Current address of R. G. Allen: Section of Ecology and Systematics, Cornell University, Ithaca, NY 14853.

Current address of A. D. Hewings: United States Department of Agriculture, Agricultural Research Service, Midwest Area, 1815 N. University Street, Peoria, IL 61604.

The use of a brand name product by the USDA implies no approval of the product to the exclusion of others that also may be suitable.

Accepted for publication 21 December 1999.

Publication no. D-2000-0218-03R

This article is in the public domain and not copyrightable. It may be freely reprinted with customary crediting of the source. The American Phytopathological Society, 2000.
25 aphid species (11). As members of the Luteoviridae family, they are small (approximately $25 \mathrm{~nm}$ ) isometric particles that contain one single-stranded RNA. They have been classified into two genera, Luteovirus (BYDV-PAV and -MAV) and Polerovirus (CYDV-RPV), based on biological properties, genome organization, and similarities of deduced amino acid sequences (6). As such, CYDV-RPV is more closely related to other poleroviruses, such as Beet western yellows virus and Potato leafroll virus (PRLV), than to luteoviruses BYDV-PAV or BYDV-MAV. Variation occurs within serotypes, across global and regional boundaries, even within regions, and appears to be quite common $(1,2,7,10,17)$.

Studies of aphid migration patterns suggest that the primary sources of BYDV inoculum in spring-sown grains in the northern United States are viruliferous aphids that are transported on low-level jet streams from southern growing areas $(13,14)$. Infections seem to spread from initial infection sites as aphids walk from one plant to another. Due to differences in the range and proportions of BYDV serotypes found in cultivated crops and perennial grasses, the role of perennial grasses as bridging or alternate hosts for BYDVs has been unclear $(3,9)$. Studies to assess the movement of BYDVs from perennial grasses to cultivated crops or from culti- vated crops to perennial grasses have been difficult in areas like Illinois because of high natural incidence of BYDV-PAV infection. Experimental data on the movement of virus within or among experimental plots often are confounded by natural infection. The objectives of this study were to investigate the variability of BYDV isolates and to identify a BYDV-PAV isolate that could be followed in field studies. Annual surveys for incidence of BYDVs in Illinois were conducted in the spring and early summer from 1990 to 1994 . BYDVPAV serotypes were the most frequently identified serotype in Illinois (5). Isolates of BYDV-MAV and BYDV-RPV serotypes also were identified. One of the BYDVPAV isolates identified in these studies, BYDV-PAV-DK1, represents one such traceable and relatively rare isolate. This paper reports the molecular and biological characterization of BYDV-PAV-IL (PAVIL) and BYDV-PAV-DK1 (PAV-DK1), a relatively rare BYDV-PAV isolate.

\section{MATERIALS AND METHODS}

Aphid vectors. Three colonies of the aphid Rhopalosiphum padi (L.) were maintained on Wysor barley (Hordeum vulgare L.) plants that were grown in chambers with a 14 -h day $\left(22\right.$ to $\left.25^{\circ} \mathrm{C}\right)$ with incandescent and fluorescent lighting and a 10 -h night $\left(14\right.$ to $\left.18^{\circ} \mathrm{C}\right)$. Two aphid colonies, $R$. padi-IL-92 and $R$. padi-ILOrg, were established from aphids collected from the field in Illinois. A third colony, $R$. padi-ID, was established with aphids collected in Idaho.

Virus isolates. Leaf samples were assayed for presence of BYDV-PAV using triple antibody sandwich enzyme-linked immunosorbent assay (TAS-ELISA) (5). Stock plants infected with viruses collected from the field were established by allowing 10 to 20 nonviruliferous $R$. padi-IL-92 aphids to feed on field samples for 2 to 3 days. Aphids were transferred to caged healthy oat (Avena sativa L.) plants at the two- to three-leaf stage, placed in the growth chambers for an additional 2 days, and killed by fumigation. Two weeks later, the plants were tested for BYDV-PAV by TAS-ELISA. BYDV-PAV isolates were named for the Illinois county from which they were collected as follows: Champaign (CN1, CN2, CN3), Clay (CY1, CY2), 
Dekalb (DK1, DK2, DK3), Edgar (EG1, EG2, EG3), Gallatin (GL1, GL2, GL3), Iroquois (IQ1), Jersey (JY1, JY2, JY3), Livingston (LV1), Madison (MD1, MD2), Ogle (OG1), Sangamon (SM1), Tazwell (TZ1, TZ2), and Will (WL1, WL2).

To analyze the nucleotide sequence similarity of the BYDV-PAV isolates, portions of the coat protein gene were amplified by polymerase chain reaction (PCR) with the Lu-1 and Lu-4 primers (19). The sizes of the amplified cDNAs were determined initially on $1 \%$ agarose gels. The amplified cDNAs then were digested individually with the restriction enzymes $A c c \mathrm{I}$, HaeIII, HinfI, Sau3AI, and TaqI (Life Technologies, Gaithersburg, MD) and analyzed on $1.4 \%$ agarose gels. To avoid sequence errors introduced while cloning, the nucleotide sequences of the cDNA from PAV-IL and four field isolates were determined directly from PCR products using primers Lu-1 (19), PAV3132 (CCC AGC GCT TTC AGA CGC), PAV3190 (CCG CCT GTT GGT CTA AA), and PAV3439 (GCC GTC ATC AAA CTG) according to the manufacturer's (United States Biochemical, Cleveland, $\mathrm{OH}$ ) instructions. The sequences were analyzed on $5 \%$ denaturing polyacrylamide gels.

Biological characterization. Two experiments were designed to measure differences between PAV-DK1 and PAV-IL in symptom severity, yield, stunting, and efficiency of aphid transmission.

Experiment 1. Oat plants were evaluated for differences in height, seed production, and number of spikelets in response to three treatments: (i) not inoculated, (ii) inoculated with PAV-IL, or (iii) inoculated with PAV-DK1. Six oat cultivars (Coast Black, Clintland64, Don, Hazel, Nobel, and Ogle) that differed in their responses to BYDV infection were selected and planted in 10-cm-diameter clay pots. Oats were planted two seeds per pot, thinned to one plant per pot, and allowed to grow in a vector-free, climate-controlled greenhouse. When plants reached the two-leaf stage, five plants of each cultivar were infested with PAV-DK1-viruliferous aphids, five were infested with 10 to 12 PAV-ILviruliferous $R$. padi-IL-92 aphids, and five were not infested. After fumigation, the plants were returned to the greenhouse and grown to maturity. At maturity, plant height and the numbers of spikelets and seeds were recorded. The experiment was conducted twice. The pooled data were evaluated using analysis of variance (ANOVA) followed by post hoc Tukey or least significant difference (LSD) tests using SAS (SAS Institute, Cary, NC).

Experiment 2. The transmission efficiencies of PAV-IL and PAV-DK1 viruses were measured using the three $R$. padi colonies mentioned above. The six treatments consisted of two viruses and three aphid biotypes. Coast Black oats, selected because the BYDV-PAV symptoms are easily identified on infected leaf tissues, were planted in 10 -cm-diameter pots as

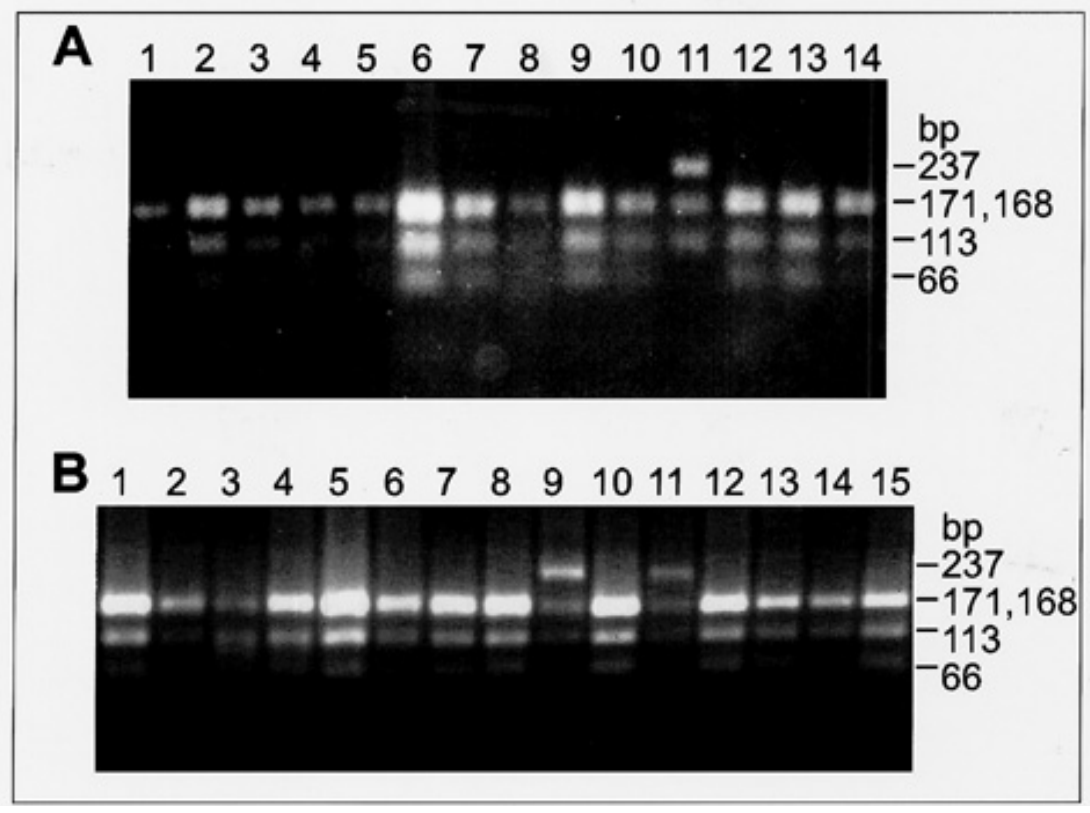

Fig. 1. Restriction fragment length polymorphism analysis of polymerase chain reaction (PCR) products from Barley yellow dwarf virus (BYDV)-PAV-like field isolates. PCR products from infected plants were digested with HaeIII and separated on 1.4\% agarose gels. (A) Isolates collected in 1991: lane 1, DK2; 2, SM1; 3, LV1; 4, CN1; 5, CN2; 6, EG1; 7, WL1; 8, CN3; 9, JY1; 10, MD1; 11, DK1; 12, JY2; 13, MD2; 14, EG2. (B) Isolates collected in 1992: lane 1, CY1; 2, CY2; 3, GL1; 4, GL2; 5, GL3; 6, EG3; 7, IQ1; 8, DK3; 9, DK1; 10, JY3; 11, TZ1; 12, TZ2; 13, OG1; 14, WL2; 15, PAV-IL. DK1 was included as a control from 1991 in lane 9. All isolates except DK1 (A lane 12, B lane 10) and TZ2 (B lane 12) have four HaeIII sites producing bands of 171, 168, 113, 66, and $13 \mathrm{bp}$. The 171- and 168-bp fragments co-migrated, and the 13-bp fragment was not detected. The DK1 and TZ2 isolates have three HaeIII sites and produce bands of 237, 168, 113, and $13 \mathrm{bp}$. above. Nonviruliferous aphids were allowed to feed on virus-infected tissue in petri dishes for approximately 2 days and then used to infest healthy seedlings. One hundred single late instar aphids from the three cultures were placed individually on 100 oat seedlings at the one- to two-leaf stage. Ten plants were not infested and were used as controls. The plants were placed in a vector-free, climate-controlled greenhouse and visually evaluated for yellowing of the leaf tissues and stunting 2 and 3 weeks after inoculation. BYD symptoms were readily apparent in most cases. In addition, infections were confirmed by TAS-ELISA. The experiment was performed twice. Data from both experiments were analyzed by $X^{2}$ tests of two-by-two contingency tables for each pair of vector-virus interactions to test for the independence of the paired treatments.

\section{RESULTS}

Restriction enzyme and sequencing analysis. All plant samples that were positive by TAS-ELISA for BYDV-PAV produced a 530-bp PCR product. When the 530-bp PCR products from the infected tissues were digested with AccI, Hinfl, Sau3AI, and TaqI, all 27 isolates had the same restriction fragment profile. However, different profiles were obtained from two isolates, one isolate from each year, when the amplified cDNAs were digested with HaeIII (Fig. 1, lanes 11A, 9B, and 11B). To further differentiate the viruses, the coat protein regions were sequenced directly from PCR products of five isolates: PAV-IL (GenBank accession AF213147), two "common" (GL2 and TZ2, GenBank accessions AF213150 and AF213148, respectively), and the two polymorphic isolates (DK1 and TZ1, GenBank accessions AF213149 and AF213151, respectively). A high level of nucleotide sequence similarity was observed among Illinois BYDV-PAV isolates from the 2 years. The sequenced regions of the viruses were greater than $98 \%$ identical. Single base substitutions within the coat protein sequences of DK1 and TZ1 were shown to be responsible for the differential cleavage pattern observed with HaeIII. HaeIII cleaves nucleic acids at GGCC sites. The substitution of a $\mathrm{T}(\mathrm{U}$ in the RNA) for a $G$ residue at position 438 leads to one fewer GGCC sites in the DK1 and TZ1 isolates. The DK1 and TZ1 cDNAs were therefore cleaved at two locations, leading to the three bands observed in Figure 1. BYDV-PAV-IL is cleaved one additional time, removing the upper band observed in the DK1 and TZ1 profiles.

Symptom expression. Plants infested with viruliferous $R$. padi all developed visible BYDV symptoms. The control plants were noticeably taller, and their leaves were darker green than the infected plants. Symptoms on infected plants in- 
cluded yellowing and leaf necrosis, obvious stunting, and in extreme cases, premature plant death.

Analysis of variance (ANOVA) revealed significant differences among the cultivars. When each cultivar was analyzed by oneway ANOVA with mean height at maturity as the dependent variable, the two viral treatments differed significantly with only one (Don) of the six oat cultivars (Table 1). The experimental treatments were not significantly different from the controls in those cultivars with higher levels of tolerance to BYDV (Hazel and Ogle).

Plants that were individually infected with the PAV-IL and PAV-DK1 did not differ significantly in their symptom expression, plant height, yield, or number of spikelets (Table 2). Coast Black oat infected with either virus isolate produced so few seeds that the number of seeds and spikelets in the different treatments could not be compared. Hence, Table 2 does not include seed and spikelet data from Coast Black oat plants.

When the two experimental groups were compared without the controls, no significant differences were found between the isolates (Table 3 ). This eliminated the possibility that the highly disparate control groups might mask significant differences between viral treatments.

Transmission efficiency. Despite the homogeneity between the two isolates in their symptom expression, they differed significantly in their rates of aphid transmission by two of the three aphid biotypes examined (Table 4). There was no significant difference in the transmission of PAVIL and PAV-DK1 by $R$. padi-IL-92, while PAV-IL was transmitted significantly better than PAV-DK1 by $R$. padi-ID and R. padiIL-Org.

\section{DISCUSSION}

The goal of these experiments was to identify an isolate of BYDV that was biologically similar to PAV-IL and that could be tracked in studies of the intra- and interfield movement of BYDV-PAV in Illinois. We evaluated 27 BYDV-PAV-like isolates collected from field locations in Illinois over 2 years and found two isolates that differed by a restriction enzyme polymorphism. The nucleotide sequences of the isolates within the amplified region were greater than $98 \%$ identical. Other studies that have examined different geographic isolates of BYDVs have reported similarly high levels of nucleotide sequence identity. Chalhoub et al. (1) compared the 3'-terminal sequences of five Australian, four French, and one Canadian PAV-like isolates. The isolates formed two groups, the first comprised of the Australian and the second of the Canadian and French isolates. The Australian isolates were all greater than $93 \%$ identical, and three of the four French isolates were greater than $98 \%$ identical. In another study of randomly selected BYDV-RMV-like isolates, the coat protein genes from Minnesota and Illinois isolates were greater than $99 \%$ identical, whereas they were only about $80 \%$ identical to a New York RMV isolate (7). However, the nucleotide sequences of the coat protein regions of Texas and New York BYDV-SGV isolates were greater than $94 \%$ identical (6). Chay et al. (2) selected isolates from the field in New York that caused more severe symptoms on Coast Black oat than NY-PAV. It is probably not surprising then that sequences were

Table 2. Comparisons of oat plants infected with Barley yellow dwarf virus (BYDV) isolates PAV-IL and PAV-DK1

\begin{tabular}{lccc}
\hline & Mean spikelets $^{\mathrm{w}}$ & Mean kernels/plant & Mean height $(\mathbf{c m})$ \\
\hline Noninoculated & $24.9 \mathrm{a}^{\mathrm{x}}$ & $35.3 \mathrm{a}$ & $79.7 \mathrm{a}$ \\
PAV-IL & $14.5 \mathrm{~b}$ & $15.3 \mathrm{~b}$ & $57.6 \mathrm{~b}$ \\
PAV-DK1 & $12.9 \mathrm{~b}$ & $14.1 \mathrm{~b}$ & $55.5 \mathrm{~b}$ \\
LSD $(5 \%)$ & 5.2 & 6.9 & 5.6 \\
CV $(\%)^{\mathrm{y}}$ & 79.1 & 85.0 & 23.9 \\
Reps $^{\mathrm{z}}$ & 169 & 169 & 174 \\
\hline
\end{tabular}

${ }^{\mathrm{w}}$ Mean number of spikelets per plant.

${ }^{x}$ Means in the same treatment that are followed by the same letter were not significantly different at $P=0.05$.

${ }^{y}$ Coefficient of variability.

${ }^{\mathrm{z}}$ Number of plants: five plants of each of six oat cultivars were subjected to three virus treatments (minus missing data). Experiment was conducted twice and data were pooled.

Table 3. Comparison of the number of spikelets and kernels per plant of oat varieties infected with Barley yellow dwarf virus (BYDV)-PAV-IL or -PAV-DK1

\begin{tabular}{lccc}
\hline & Mean spikelets & Mean kernels/plant & Mean height \\
\hline PAV-IL & 14.5 & 15.3 & 57.6 \\
PAV-DK1 & 12.9 & 14.1 & 55.5 \\
& $\mathrm{~N}^{\mathrm{z}}=110$ & $\mathrm{~N}=110$ & $\mathrm{~N}=115$ \\
Probability & 0.51 & 0.70 & 0.53 \\
\hline
\end{tabular}

${ }^{\mathrm{z}}$ Number of plants: five plants of each cultivar were infected with each virus isolate (minus missing data). Experiment was conducted twice and data were pooled.

Table 4. Efficiencies of aphid transmission of Barley yellow dwarf virus (BYDV)-PAV-IL and -PAVDK1

\begin{tabular}{|c|c|c|c|c|}
\hline Vector & Viral isolates & $(\%)$ transmission $^{z}$ & $X^{2}$ & Probability \\
\hline \multirow[t]{2}{*}{ Rhopalosiphum padi-IL-92 } & PAV-IL & 61.0 & 0.92 & $P>0.10$ \\
\hline & PAV-DK1 & 67.5 & & \\
\hline \multirow{2}{*}{ R. padi-IL-Org. } & PAV-IL & 80.0 & 13.00 & $P \ll<0.001$ \\
\hline & PAV-DK1 & 55.5 & & \\
\hline \multirow[t]{2}{*}{ R. padi-ID } & PAV-IL & 73.5 & 9.00 & $P<<0.001$ \\
\hline & PAV-DK1 & 52.0 & & \\
\hline
\end{tabular}

${ }^{z}$ Percent plants infected after single aphid inoculation with the designated virus isolate. Data were pooled from two experiments, each with 100 plants, with 100 single aphids for each aphid colony.

Table 1. Comparison plant height at maturity of oat cultivars infected with Barley yellow dwarf virus (BYDV)-PAV-IL or -PAV-DK1

\begin{tabular}{|c|c|c|c|c|c|c|}
\hline & \multicolumn{6}{|c|}{ Oat cultivars } \\
\hline & Coast Black & Clintland 64 & Don & Hazel & Noble & Ogle \\
\hline Noninoculated & $82.9 \mathrm{a}^{\mathrm{x}}$ & $80.3 \mathrm{a}$ & $82.4 \mathrm{a}$ & $77.9 \mathrm{a}$ & $76.1 \mathrm{a}$ & $81.2 \mathrm{a}$ \\
\hline PAV-IL & $30.3 \mathrm{~b}$ & $46.2 \mathrm{~b}$ & $64.1 \mathrm{~b}$ & $70.0 \mathrm{a}$ & $51.3 \mathrm{~b}$ & $78.7 \mathrm{a}$ \\
\hline PAV-DK1 & $31.1 \mathrm{~b}$ & $54.1 \mathrm{~b}$ & $56.9 \mathrm{c}$ & $69.1 \mathrm{a}$ & $46.1 \mathrm{~b}$ & $70.7 \mathrm{a}$ \\
\hline $\operatorname{LSD}(5 \%)$ & 7.8 & 10.5 & 7.4 & 10.2 & 7.1 & 10.5 \\
\hline $\mathrm{CV}(\%)^{\mathrm{y}}$ & 16.5 & 17.9 & 11.9 & 15.3 & 13.1 & 14.6 \\
\hline $\operatorname{Reps}^{z}$ & 29 & 28 & 30 & 30 & 29 & 30 \\
\hline
\end{tabular}

${ }^{\mathrm{x}}$ Mean heights for each cultivar that are followed by the same letter were not significantly different at $P=0.05$.

${ }^{y}$ Coefficient of variability.

${ }^{\mathrm{z}}$ Number of plants: five plants of each cultivar were subjected to three virus treatments (minus missing data). Experiment was conducted twice and data were pooled. 
about $90 \%$ identical to New York and Indiana isolates of BYDV-PAV.

Even though the symptom expression and coat protein nucleotide sequences of the PAV-DK1 and PAV-IL isolates were very similar, PAV-IL was transmitted more readily than PAV-DK1 by two of the three aphid biotypes. Overall, PAV-DK1 was transmitted with a total efficiency of $58 \%$, and PAV-IL was transmitted with $72 \%$ efficiency. By vegetatively transferring PLRV for several generations, Jolly and Mayo (16) produced a poorly aphid-transmitted PLRV isolate that was transmitted with an efficiency of only $12 \%$ compared with $75 \%$ for a highly transmitted isolate. This difference in transmission efficiency was correlated with two amino acid changes in the readthrough domain of the coat protein. While PAV-DK1 was transmitted less efficiently than PAV-IL, it retained $82 \%$ of PAV-IL's overall transmission efficiency, much higher than that of the poorly transmitted PLRV isolate. The predicted amino acid sequences of the two PAV isolates differed at just three of the 171 positions within the $22-\mathrm{kDa}$ coat regions. The differences in aphid transmission between PAV-DK1 and PAV-IL may be due to amino acid sequence differences in the open reading frame that encodes the readthrough domain of the coat protein, which has been shown to be involved in aphid transmission $(16,18,20)$. The lower incidence of PAV-DK1 relative to the more prevalent PAV types could result from PAV-DKl's lower transmission efficiency. It is possible that PAV-DKl's transmission efficiencies may be lower under conditions that have not been optimized for high virus titers. Other factors that could influence aphid transmission efficiency, such as vector preferences, were not compared in this study.

The migration of viruliferous aphids into growing areas is thought to play an important role in BYDV epidemiology $(13,14)$. Yet conducting epidemiological studies of BYDV infection in areas that routinely have a high incidence of natural BYDV infections can be difficult. The serological techniques employed to detect BYDV infections typically cannot differentiate between artificially induced and naturally occurring infections. Data on the movement of viruses within or among fields can be confounded by natural infections since the source of virus cannot be identified. A relatively rare BYDV isolate, PAV-DK1, was shown to have a different DNA fragment profile than the most common Illinois isolate, PAV-IL, when the PCR products representing a portion of the coat protein gene were digested with the restriction enzyme HaeIII. This difference in PCR profiles could be exploited to differentiate the PAV-DK1 isolate from the more prevalent Illinois isolates. Thus, the use of PAV-DK1 or other isolates of low incidence could permit field epidemiological studies in locations like Illinois that annually have a high incidence of BYDV infection. For example, this would allow investigators to track intrafield virus spread from inoculation foci. Because cross protection is observed among some BYDV serotypes $(15,22)$, it is likely that extensive prior infection by more predominant PAV types could limit the ability of DK1 to infect plants. Yet the similarity between PAV-DK1 and predominant Illinois isolates makes its benefits as a traceable isolate clear.

\section{ACKNOWLEDGMENTS}

We thank George Gregerson for assistance in the production of plant materials and maintenance of the aphid colonies used in these studies.

\section{LITERATURE CITED}

1. Chalhoub, B. A., Kelly, L., Robaglia, C., and Lapierre, H. D. 1994. Sequence variability in the genome 3 -terminal region of BYDV for 10 geographically distinct PAV-like isolates of barley yellow dwarf virus - analysis of the ORF6 variation. Arch. Virol. 139:403-416.

2. Chay, C. A., Smith, D. M., Vaughan, R., and Gray, S. M. 1996. Diversity among isolates within the PAV serotype of barley yellow dwarf virus. Phytopathology 86:370-377.

3. Comeau, A., and Dubuc, J. P. 1977. Observations on the 1976 barley yellow dwarf epidemic in eastern Canada. Can. Plant Dis. Surv. 57:42-44.

4. Conti, M. C., D'Arcy, C. J., Jedlinski, H., and Burnett, P. A. 1990. The "Yellow Plague" of cereals, barley yellow dwarf. Pages 1-6 in: World Perspectives on Barley Yellow Dwarf. P. A. Burnett, ed. CIMMYT, Mexico City D.F.

5. D'Arcy, C. J., Hewings, A. D., and Eastman, C. E. 1992. Reliable detection of barley yellow dwarf viruses in field samples by monoclonal antibodies. Plant Dis. 76:273-276.

6. D'Arcy, C. J., and Mayo, M. 1997. Proposals for changes in luteovirus taxonomy and nomenclature. Arch. Virol. 142:1285-1287.

7. Domier, L. L., Lukasheva, L. I., and D'Arcy, C. J. 1994. Coat protein sequences of RMVlike strains of barley yellow dwarf virus separate them from other luteoviruses. Intervirology $37: 2-5$.

8. Eisbein, K., and Habekuss, A. 1990. Notches on leaves of barley infected with barley yellow dwarf virus. Arch. Phytopathol. Pflanzen- schutz 26:197-200

9. Fargette, D., Lister, R. M., and Hood, E. L. 1982. Grasses as a reservoir of barley yellow dwarf virus in Indiana. Plant Dis. 66:10411045.

10. Geske, S. M., French, R., Robertson, N. L., and Carroll, T. W. 1996. Purification and coat protein gene sequence of a Montana RMVlike isolate of barley yellow dwarf virus. Arch. Virol. 141:541-556.

11. Halbert, S., and Voegtlin, D. 1995. Biology and taxonomy of vectors of barley yellow dwarf viruses. Pages 217-258 in: Barley Yellow Dwarf: 40 Years of Progress. C. J. D'Arcy and P. A. Burnett, eds. American Phytopathological Society, St. Paul, MN.

12. Harder, D. E., and Harber, S. 1992. Barley yellow dwarf virus. Page 379 in: Oats Science and Technology. H. G. Marshall and M. E. Sorrells, eds. American Society of Agronomy, Madison, WI

13. Hewings, A. D., and Eastman, C. E. 1995 Epidemiology of barely yellow dwarf in North America. Pages 75-106 in: Barley Yellow Dwarf: 40 Years of Progress. C. J. D'Arcy and P. A. Burnett, eds. American Phytopathological Society, St. Paul, MN.

14. Irwin, M. E., and Thresh, J. M. 1990. Epidemiology of barley yellow dwarf: A study in ecological complexity. Annu. Rev. Phytopathol. 28:393-424.

15. Jedlinski, H., and Brown, C. M. 1965. Cross protection and mutual exclusion by three strains of barley yellow dwarf virus in Avena sativa $\mathrm{L}$. Virology 26:613-621.

16. Jolly, C. A., and Mayo, M. A. 1994. Changes in the amino acid sequence of the coat protein readthrough domain of potato leafroll luteovirus affect the formation of an epitope and aphid transmission. Virology 15:182-185.

17. Lei, C.-H., Lister, R. M., Vincent, J. R., and Karanjkar, M. N. 1995. SGV serotype isolates of barley yellow dwarf virus differing in vectors and molecular relationships. Phytopathology 85:820-826.

18. McGrath, P. F., Lister, R. M., and Hunter, B. G. 1996. A domain of the readthrough protein of barley yellow dwarf virus (NY-RPV isolate) is essential for aphid transmission. Eur. J. Plant Pathol. 102:671-679.

19. Robertson, N. L., French, R., and Gray, S. M. 1991. Use of group-specific primers and the polymerase chain reaction for the detection and identification of luteoviruses. J. Gen. Virol. 72:1473-1477.

20. Wang, J. Y., Chay, C., Gildow, F. E., and Gray, S. M. 1995. Readthrough protein associated with virions of barley yellow dwarf luteovirus and its potential role in regulating the efficiency of aphid transmission. Virology 206:954-962

21. Waterhouse, P. M., Gildow, F. E., and Johnstone, G. R. 1988. The luteovirus group. Page 9 in: CMI/AAB Descriptions of Plant Viruses. Commonw. Mycol. Inst./Assoc. Appl. Biol., Kew, England.

22. Wen, F., Lister, R. M., and Fattouh, F. A. 1991. Cross-protection among strains of barley yellow dwarf virus. J. Gen. Virol. 72:791799. 